
\title{
3 Research Soure \\ Comparisons of Health-Related Quality of Life and Impact Factors in Patients with Depression and Schizophrenia
}

Chonghua Wan ( $\square$ wanchh@hotmail.com )

Guangdong Medical University https://orcid.org/0000-0002-7323-6837

Jingjing Zhang

Kunming Medical University

Yan Lin

Kunming Medical University

Keying Zhao

Kunming Medical University

Jiahong Luo

Kunming Medical University

Jianfeng Tan

Guangdong Medical University

Xudong Zhao

tongji university

Research article

Keywords: Health-related quality of life (HRQOL), Impact factors, Depression, Schizophrenia, Comparison

Posted Date: September 2nd, 2020

DOI: https://doi.org/10.21203/rs.3.rs-23475/v1

License: (1) This work is licensed under a Creative Commons Attribution 4.0 International License. Read Full License 


\section{Abstract}

Background: Depression and schizophrenia are the global common causes worldwide of long-term and devastating disability, which significantly impact the patient quality of life. This paper is aimed to analyze and compare the health-related quality of life (HRQOL) of patients with Depression and Schizophrenia, determine main impact factors of their HRQOL with these two diseases and try to distinct the difference of impacts at socio-demographic \socioeconomic and medical level.

Methods: 204 out-patients and in-patients diagnosed Depression or Schizophrenia according to Chinese classification and diagnostic criteria of mental disorders (CCMD-3) were sampled, who were volunteering to participate and can understand the meaning of questionnaires with accordance of the included criteria. The Health survey questionnaire (SF-36) and self-administered measurements were used to appraisal the subjective health status, the disease characteristics and other relevant medical potential predictors of participants.

Results: All of the domain scores of SF-36 of patients with Depression and Schizophrenia are both lower than healthy people and there are significant differences in all domains, compared with depression group, most domains of SF-36 in Schizophrenia group are lower besides the body pain (BP) and social function (SF), and are difference in domains of role physical (RP) and mental health $(\mathrm{MH})$ between two patient groups. For depression group, the predictors of unmarried status, subject change of health status and depression degree are correlated to HRQOL in PCS, the predictors of unmarried status, ethnicity and duration of disease are correlated to HRQOL in MCS. For schizophrenia group, predictors of subjective change of health status, family annual income, educational level, severity degree and ethnicity are associated with HRQOL in PCS, only predictor of ethnicity is associated with HRQOL in MCS.

Conclusion: The HRQOL of patients was likely be impacted by the factors at both socio-demographic and medical level, but the functions of the same factors were different between depression and schizophrenia.

\section{Background}

Mental health problem is a critical issue due to the higher increasing prevalence, and depression and schizophrenia are included among the global common causes worldwide of long-term and devastating disability, which significantly impact the patient quality of life, with wide ranging and long-lasting impact for people suffering from the illness, their families, social services and the wider economy meanwhile[1-3]. It is estimated that there are 350 million and 24 million people suffering from depression and schizophrenia worldwide respectively according to the World Health Organization[4]. China is also facing this challenge of more than 26 million and 7.8 million people who are suffering from depression and schizophrenia respectively, and between the two disastrous diseases, depression is becoming a more serious issue with highest disease burden estimated in 2030[5,6].

Depression, to some extent, similar as schizophrenia, is a series of chronic condition characterized by an early onset, usually during adolescence, severe symptomatology and chronic course[7-9], however, there are no more specific symptoms of these two diseases to be found besides the similarity in depressed mood at the prodromal stage of these two diseases[10], many of patients are failure to be recognized in clinical settings, 
diagnosed or medical treated properly[11,12], therefore, it is more vague and difficult to capture these people from general group and distinguish each other. More unfortunately, some patients are also failure to stick to accept therapeutic, psychological treatment or inadequacies of treatment services contributing from lower socioeconomic support $[13,14]$. The difficulties in availability, accessibility, and acceptability as well are the consequent problems which increase the burden to patients and their family with these two diseases.

The previous research suggests that due to its chronic nature and continuous impairment, the main aim of health and social care interventions is to improve symptoms, long-term health, and quality of life, reduce economic burden to patients, families and society $[15,16]$. The treatments focus on the medical and sociopsycho-therapy to mange this illness. Although it is entirely appropriate try to use multiple resources in helping those people, there are inevitable pressures to manage their illness as effectively as possible. Some researches indicate there are still some heterogeneity results in similar intervention program to these two diseases[17,18]. Not all integrated therapeutic approaches are proved to be feasible to both of patients with depression or schizophrenia, and the outcomes imply that there are some differences in the pathogenesis of depression or schizophrenia[19,20].

In addition, in China, although government has put forward a serious of policies to manage the mental disorder patients, there is not still the same sound on some policy, such as the Compulsory Hospitalization Program (CHP) and how to manage these patients who are with mild and moderate disease degree in community more effectively.

Quality of life measurements are increasingly considered to be an important evaluation of the treatment and care provided to patients with mental diseases. "Health-related quality of life (HRQOL)" s defined as an individual's satisfaction or happiness with domains of life as far as they affect or are affected by health. It is concerned primarily with those factors that fall under the purview of health care providers and health care systems and in health care[21]. Using of HRQOL measures may contribute to better adherence to therapeutic interventions, more satisfaction with care, improved health outcomes and reduction of health costs, HRQOL assessment remains underutilized in clinical practice, HRQOL researchers, the medical community and decision makers[22,23]. Although there are some researches imply there may be correlation between determinants and HRQOL of patients with depression or schizophrenia, there are still deficiency of evidence of comparison of HRQOL of patients suffered from different mental disorders and meanwhile it is plague that whether depression patients are as different impact factors of HRQOL at socio-demographic, socioeconomic and medical level as the compared patients with schizophrenia and how these different impacts on the different dimension of HRQOL, such as in physical and mental dimensions.

This study tries to compare the HRQOL of patients with depression and schizophrenia and impact factors at socio-demographic, socioeconomic and medical level, determine the potential predictive factors in internal dimensions of HRQOL, explore the relevant association between predictors and different dimensions of HRQOL and provide more evidence of multi-level intervention and specific management of mental disease and give some suggestions of policy making.

\section{Methods}




\section{Ethical statement}

This study is approved by the Human Experiment and Ethics Committee of Kunming Medical University and Kunming city mental hospital, and the participants are interviewed after their informed consent is obtained. Each of these special patients was required to sign a written informed consent.

\section{Settings and participants}

Total 309 out-patients and in-patients, who were diagnosed Depression or Schizophrenia according to Chinese classification and diagnostic criteria of mental disorders (CCMD-3) first, are randomly sample in the first affiliated hospital of Kunming Medical University and Kunming city mental hospital, and then 253 subjects are recruited, who are volunteer to participate and they or their relatives can understand the meaning of questionnaires with accordance of the included criteria. Those not sticking to finish our survey are withdrawal our study. Overall, there are 204 participants to be finally recruited, who are 60 male and 75 female patients in depression group, 31 male and 38 female patients in schizophrenia group respectively. Those with poor cognitive function, or having severe physical diseases or serious physical impairment are excluded. Meanwhile, 136 healthy people being diagnosed by doctors who come to the same hospital to do physical examination with similar demographic characteristics in gender and age are selected in control group.

\section{Socio-demographic data}

Participants' age, gender, education level, marital status, resident areas, family income status and parenthood status are recorded.

\section{Participants' subjective health status}

\section{Subjective health-related quality of life}

Subjective health-related quality of life is appraisal using the Health survey questionnaire (SF-36), which is used in numerous diseases and with moderate reliability and validity and have moderate multicultural adaptability[24,25]. This 36-item questionnaire measures eight health concepts: Physical Functioning (ten items), Role Physical (four items), Bodily Pain (two items), General Health (five items), Vitality (four items), Social Functioning (two items), Role Emotional (three items), Mental Health (five items), and one item of Reported Health Transition. The eight concepts could be grouped into Physical Component Summary (PCS) and Mental Component Summary (MCS) measures, which represent subjective physical health and mental health, respectively. PCS and MCS are rated according to the SF-36 users' manual.

\section{Subjective change of health status}

Subjective change of health status of the recent year is also assessed by one item, and the term of this item is "What do you think about your health status during the recent year?" A 5-point scale rated this item, ranging from "mostly change worse" to "mostly change better".

\section{Major characteristics of depression and schizophrenia}


Participants are also to record the main characteristics of depression and schizophrenia we study and the critical life events in recent one year, and the main characteristics of these two diseases included the family history of cases, course of disease, onset form, severity of disease, duration of depression/schizophrenia and treatment duration. The critical life is assessed by one item, which is "Did you experience critical life events (which are as following choices) or not?" Binary answer choice is scaled with "no" and "yes".

\section{Survey Procedures}

The investigators conduct personal interviews with half-structured questionnaires in participants' wards alone to collect related data. Due to the participants' age and the time consuming nature of completing the questionnaires, if they feel tired or uncomfortable, the interview will be paused until they indicate that they are ready to continue. If participants not remember clearly or forget some contents, their relatives who know it can substitute them to answer.

\section{Data analysis}

Data analysis including descriptive and inferential statistics is performed using SPSS, version 17.0 (SPSS Inc., Chicago, IL, USA). Categorical variables are presented as frequencies and percentages, while continuous variables are presented as mean \pm standard deviation. Discriminative validities for HRQOL between disease groups and norm are evaluated by Student's t-test and ANOVA. Univariate analyses are done, followed by socio-demographic characteristics. Stepwise multiple linear regression analysis is used to analyze the potential impact factors and their predictive functions of HRQOL in PCS and MCS.

\section{Results}

\section{Subject socio-demographics characteristics}

Totally 204 participants complete the interview alone or by their relatives. The average time of interviewing is about 40-45 minutes. Not so clearly answers are not to be recorded. Table 1 and Table 2 summarize sociodemographics characteristics of participants and main characteristics of depression and schizophrenia.

The ages of the $135(66.2 \%)$ patients with depression range from16 to 73 years, with an average of $39.17 \pm$ 13.80 years; The ages of the 69 (33.8\%) patients with schizophrenia range from16 to 74 years, with an average of $33.00 \pm 14.09$ years. Sixty (44.4\%) male and seventy five (55.6\%) female patients are in depression group, and thirty one (44.9\%) male and thirty eight (55.1\%) female patients are in schizophrenia group. Meanwhile, one hundred and thirty six healthy people are selected as control group, which were composed with 64 male and 72 female participants (Table 1 in detail).

\section{Main characteristics of depression and schizophrenia}

The duration of disease in depression group is ranged from 0.2 to 20.3 years, with an average of $4.44 \pm 4.12$, and the duration of disease in schizophrenia group is ranged from 0.1 to 39.8 years, with an average of $5.58 \pm$ 7.31. There are seventy nine (58.5\%) acute/sub-acute patients and fifty six (42.5\%) chronic patients in depression group, and forty six (66.7\%) acute/sub-acute patients and twenty three (33.3\%) chronic patients in schizophrenia group. Nearly sixty (59.3\%) patients of depression degree in depression group are in moderate 
level versus more than sixty six (66.7\%) at the same severity of disease level in schizophrenia group. The treatment duration is in average of $3.30 \pm 5.40$ years and $4.20 \pm 6.05$ years in depression and schizophrenia groups respectively (Table 2 in detail).

\section{Univariate statistical comparison of socio-demographic predictors: HRQOL of patients in depression and schizophrenia}

The table 3 shows HRQOL dimension scores of patients with depression and schizophrenia compared among different relevant socio-demographic characteristics. The outcomes show that there are associations between socio-demographic characteristics of gender, ethnicity, education and marital status of patients and HRQOL of patients.

1) Comparison of HRQOL of dimension scores of patients with depression and Schizophrenia between male and female group

There is only difference in HRQOL of social functioning (SF) dimension score of patient with depression $(t=-2.349, P=0.020)$ and difference in HRQOL of physical functioning (PF) dimension score of patient with schizophrenia $(t=-2.175, P=0.033)$ respectively between male and female group. No differences in other dimension scores were found in both depression and schizophrenia patients $(P>0.050)$. The result indicates that the social function of female patients with depression is more likely to be better than that of male patients, whereas, the physical function of male patients with schizophrenia is more likely to be better than that of female patients, but there are not quite differences in HRQOL of other dimensions of all patients between male and female group.

2) Comparison of HRQOL of dimension scores of patients with depression and Schizophrenia in different ethnic groups

No difference in HRQOL of all dimension scores of patients with schizophrenia is found $(P>0.050)$ between Han and minority group. There are differences of total score and the dimension score of PF of patients with depression between Han and other minority groups $(t=-2.067, P=0.041 ; t=-3.323, P=0.001)$. It is illuminate that the total HRQOL and the physical function of patients with depression in minority group is more likely better than that of patients in Han group.

3) Comparison of HRQOL of dimension scores of patients with depression and Schizophrenia at different educational level

In depression patients, there are differences of total score, the dimension scores of $\mathrm{PF}$, bodily paining (BP) and $\mathrm{SF}$ in different educational level groups $(F=-5.298, P=0.006 ; F=3.586, P=0.030 ; F=6.932, P=0.001 ; F=$ $5.578, P=0.005)$ and in schizophrenia patients, only difference of HRQOL of dimension of role emotional (RE) is found $(F=3.750, P=0.029)$. The result indicates that the higher educational level of patients with depression, the better HRQOL would they have, especially in the dimension of PF, BP and SF, whereas, the higher educational level of patients with schizophrenia, the worse HRQOL of RE would they have.

4) Comparison of HRQOL of dimension scores of patients with depression and schizophrenia among different marital status groups 
No difference of all dimension scores on HRQOL of patients with schizophrenia is found $(P>0.050)$. Whereas, there are differences of total score, the dimension score of $\mathrm{PF}, \mathrm{GH}$ and $\mathrm{RE}$ of patients with depression among different marital status groups $(F=3.116, P=0.048 ; F=4.073, P=0.019 ; F=3.886, P=0.023 ; F=4.466, P=$ 0.013). The result manifests that compared with other groups, the dimension of $P F$, general health $(\mathrm{GH}), \mathrm{RE}$ and the general HRQOL of patients with depression who are unmarried are more likely better.

\section{Participants' subjective health status}

The participants' subjective health status and the comparison of domain scores of SF-36 in patients with depression/schizophrenia to healthy group are shown in Table 2. The total score, PCS score and MCS score and all domain scores of SF-36 in three groups (patients with depression, schizophrenia and healthy population) are different each other through the S-N-K ANOVA analysis. The patients groups are both lower than those of general group and there are significant differences in all domains $(P<0.001)$. Compared with schizophrenia group, most domains scores of SF-36 in depression group are slightly higher besides of BP and $\mathrm{SF}$, and there were differences in the domains of Role physical (RP) and Mental health (MT) between two groups $(P<0.001)$ (Table 4 in detail).

\section{Correlation of the main predictors and HRQOL of patients with Depression and Schizophrenia using multiple linear regression analysis}

The stepwise multiple linear regression models is used to analyze the correlation of potential impact factors and HRQOL of participated patients by manner of entering variable probability of 0.05 and the removing of 0.10. The predictors of HRQOL in PCS and MCS for patients with depression and schizophrenia are also analyzed respectively. As the HRQOL of PCS and MCS in patients with depression are the dependence 1 and dependence 2 respectively. The HRQOL of PCS and MCS in patients with schizophrenia are to be dependence 3 , dependence 4 respectively. The potential impact factors in socio-demographic, socio-economic and medical level are selected to be the independence. The eighteen independence variables are selected, the quantization listed in the table 6.

Table 6 summarizes the results of stepwise multiple linear regression models to analyze predictors of HRQOL in PCS and MCS for patients with depression and schizophrenia. Concerning the stepwise multiple liner regression analysis on the Physical Component Summary (PCS) as the dependent variable Y, Mental Component Summary (MCS) as the dependent variable Y, respectively, the results indicate that HRQOL in PCS

of depression is negative correlated to the change of health status and depressive degree and positive correlated to unmarried status, the regression equation model is ${ }_{1}(\mathrm{PCS})=73.14-2.89 \mathrm{X}_{16}-3.21 \mathrm{X}_{14}+3.02 \mathrm{X}_{4}$, this model explained twenty percent $(20 \%)$ of the variance of HRQOL in PCS of depression with adjusted $\mathrm{R}$ Square $=0.20, F=7.38, P=0.00$. The HRQOL in MCS of depression is positive correlated to unmarried status, ethnicity and duration of disease, the regression equation model is ${ }_{2}(M C S)=42.55+4.04 \mathrm{X}_{4}+4.50 \mathrm{X}_{3}+0.35 \mathrm{X}_{13}$, this model explained eleven percent $(11 \%)$ of the variance of HRQOL in MCS of depression with adjusted $\mathrm{R}$ Square $=0.11, F=7.11, P=0.00$.

Annual family income, severity degree of patient is positive correlate with HRQOL in PCS of schizophrenia, change of health status, ethnicity, educational level are negative correlate, the regression equation model is ${ }_{3}(P C S)=72.70-2.11 X_{16}+1.97 X_{8}-5.51 X_{7}+6.28 X_{14}-10.19 X_{3}$, thirty six percent $(36 \%)$ of the variance of HRQOL in 
PCS of schizophrenia can be explained with Adjusted R Square $=0.11, F=7.11, P=0.00$, and only one parameter, ethnicity, is negative correlate to HRQOL in MCS with standardized beta coefficients of -0.28 , the regression equation model is ${ }_{4}(P C S)=57.97-6.80 X_{3}$, the fourth model can explain six percent $(6 \%)$ of the variance of HRQOL in MCS of schizophrenia with adjusted $R$ Square $=0.06, F=7.34, P=0.02$.

\section{Discussions}

Mental disorder patients mostly suffer from the dramatically long-lasting disease impairment including depression and schizophrenia and are more likely to result in poor HRQOL. Our results manifests that HRQOL of patients with depression and schizophrenia are still worse than healthy people even they have been delivered some clinical therapy. Moreover, the outcomes show that HRQOL of patients with schizophrenia seems to be worse than depression group especially in HRQOL domains of RP and $\mathrm{MH}$. In addition, as depression is a frequently occurring symptom in schizophrenia, and there are some similarities at their prodromal stage, it is still difficult to diagnose and patients are more vulnerable to be mistreated.

HRQOL measurements are increasingly considered to be an important evaluation of the treatment and care provided to patients with mental diseases. The internal difference implies that the hypothesis of different impairment of factors on HRQOL would likely be in.

The socio-demographic and socioeconomic factors are considered to be correlated to their HRQOL and these sorts of factors play an important role in the mental disorder patients HRQOL[26]. The results of univariate analysis in our research show there are more than one factor may impact the HRQOL of patients in two patient groups at social-demographic and socioeconomic level, the majority factors referred to gender, ethnicity, educational level, marital status and annual family income.

However, some studies get the different outcomes. Some previous research find that social-demographic and socioeconomic factors may not the only sorts of factors impact the HRQOL of patients and it seems not to have the most important role in schizophrenia[27]. In our study, when separately analyzing the relationships between impact factors and the physical component summary (PCS), mental component summary (MCS) of HRQOL respectively, there are some interesting outcomes are found. The multiple linear regression analysis outcomes indicate that although there are multi-level factors impacting HRQOL of patients, both of depression and schizophrenia groups are influenced by demo-socio-medical factors, there are different relationships between social-demographic and medical factors and some reverse effective functions in the same factors, and only one socioeconomic predictor, the annual family income, is impact the HRQOL of PCS of patient with schizophrenia.

In depression group, results indicate that unmarried patients who appraisal their health status better in a recent year and less depression degree are more likely to have better HRQOL in PCS; and the patients in minority group with shorter duration of disease are more likely to have better HRQOL in MCS. Generally, the most impacted factors on HRQOL of depression patients can be concluded in three-level factors, the subjective appraisal of changing health status in recent year, the disease characteristics and marital status and the predictor of unmarried status are both associated with HRQOL in PCS and MCS. 
Compared with depression group, it seems to have more multi-level factors relative to HRQOL of patients with schizophrenia, the results illuminate that patients in Han group with characteristics of better recent health status, less disease severity degree, higher family annual income, lower educational level are more likely to have better HRQOL in PCS, additionally, patients in Han group is more likely to have better HRQOL in MCS, the main potential predictors on HRQOL of patients with schizophrenia would be referred to all of the levels we study included socio-demographic, socioeconomic and medical factors, such as subjective appraisal of changing health status in recent year, the economic, medical and demographic aspects, whereas, the ethnicity was the only predictor relative to HRQOL in PCS and MCS.

And more interestingly, the socio-demographic of ethnicity and medical factor of degree of disease have opposite impact functions on the HRQOL between these two patient groups. An interesting result is also found that the more severe the degree of schizophrenia is in onset, the higher score of HRQOL is, this result is similar with some result in China, however, it seems to be opposite conclusion with the study of Hamaideh S, which show that it is correlated positively with patients education, negatively with severity of psychiatric symptoms[27]. It also indicate that there may be some heterogeneous reasons in same factor we are not determined. In our study, ethnicity seems to be one of the most important socio-demographic factors which are both impact the HRQOL of PCS and MCS of patients. Some similar results are found in other researches and try to explain the reason deduced from culture[28],but whether the difference is attribute to external different culture environment or internally genetic etiology of ethnicity or not should need more evidence. Additionally, compared with depressed patients, only HRQOL in PCS of patients with schizophrenia seemed to be impacted by the economic factor when we separated analyze in PCS and MCS. This outcome show that the HRQOL of patients with schizophrenia may be more strongly relative to their family economic burden, especially in physical health. It may be refer to the more relatively irreversible change in pathological process of schizophrenia compared with depression, the more serous impact in pathology on schizophrenia patients may be due to their poorer HRQOL[28-30].

Although the social-demographic, socioeconomic and medical factors are likely to impact the HRQOL of patients, some internal factors may be still not found which are likely to impact HRQOL of patient in etiology. In our research, the explanation of multi-level predicators and HRQOL of patients with depression or schizophrenia is just range from six to thirty six percent. The similar results also can be found in other previous researches[26,27].

In addition, some previous researches show that there may be some difference outcomes on HRQOL when patients with depression or schizophrenia are delivered similar intervention[29,30]. The outcomes of our study also indicate that although there are similar patterns of relationship between impact factors and HRQOL, there are quite different functions of the same factors in the two patient groups.

Above outcomes imply that the function of the same factors might not have the same affection, there may be some differences in etiology between depression and schizophrenia and more specific multi-level intervention to each of these two diseases should be needed[31]. Due to the higher rate of clinical unrecognizing, the condition of depression and schizophrenia in general people is likely to be more worried about[32]. And in terms of availability, accessibility, and acceptability, theses "invisible" patients are more vulnerable to be attached by risk factors, such as inadequate treatment services, lower socioeconomic status (SES) and then 
unfortunately with worse HRQOL[13,14,26,27]. Much information in our research supplied may help the physician and the policy maker to manage these two quite different mental diseases more clearly.

\section{Limitation}

There are some limitations in the present study. The cross-sectional design does not allow inference of causality. It is possible to explore associations, identification of predictors and their effects on HRQOL, but not to determine causal effects. Follow-up studies would be required to address this issue. Moreover, this study is just based in hospital samples, epidemiological study in general people should be needed to explain the inner reason as a whole. Given some heterogeneous results, more longitudinal research should be needed.

\section{Conclusion}

In this study, socio-demographic, socioeconomic and medical factors are influence the HRQOL of patients with depression and schizophrenia in different way. Given the special characteristics in the two groups, it is urgent to deliver more specific interventions at multi-level respectively[33,34]. Providing these patients with adequate and continuous interventions at family and community level to improve their poor HRQOL seems to be better than simple clinical and single level intervention strategy[35].

\section{Abbreviations}

HRQOL: health-related quality of life, CCMD :Chinese classification and diagnostic criteria of mental disorders,

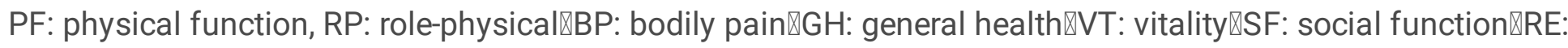
role-emotional囚MH: mental-health, PCS: Physical Component Summary, MCS: Mental Component Summary.

\section{Declarations}

\section{Ethics approval and Consent to participate}

The study protocol and the informed consent form were approved by the IRB (institutional review board) of Kunming Medical University (30860248, Kunming Medical University, 01/17/2009).

The respondents were voluntary and provided written consent for participation.

\section{Consent for publication}

Not Applicable.

\section{Availability of data and material}

Not applicable.

\section{Competing interests}

None declared. 


\section{Funding}

The paper is supported by the National Natural Science Foundation of China $(71373058,30860248)$, Science and Technological Planning Program of Guangdong Province (2013B021800074). These funds had the role in the study design, data collection, analysis and interpretation of data, with the National Natural Science Foundation of China $(71373058,30860248)$ supporting all tasks and the Science and Technological Planning Program of Guangdong Province (2013B021800074) only supporting analysis and interpretation of data, and also manuscript writing.

\section{Authors' contributions}

WCH, ZJJ and ZXD designed the study. LY, ZKY, MQ performed the data collection and WCH,ZJJ performed data analyses, and all authors contributed to interpreting the data. WCH and ZJJ wrote the first draft, which was critically revised by all others. All authors have read and approved the final manuscript.

\section{Acknowledgements}

In carrying out this research project, we have received substantial assistance from the staff of the Kunming Medical University and the first Affiliated Hospital of Kunming Medical University, including Qiong Meng, Yong Mao, Xiufeng Xu, Yong Zeng, etc. We sincerely appreciate their kind help.

\section{References}

1. Charlson FJ, Ferrari AJ, Flaxman AD, Whiteford HA. The epidemiological modeling of dysthymia: Application for the Global Burden of Disease Study 2010. J Affect Disord. 2013; 151(1):111-120.

2. Boyer L, Lançon C, Baumstarck K, Parola N, Berbis J, Auquier P... Evaluating the impact of a quality of life assessment with feedback to clinicians in patients with schizophrenia: randomised controlled trial. $\mathrm{Br} \mathrm{J}$ Psychiatry. 2013; 202:447-453.

3. Reynolds CF 3rd, Cuijpers P, Patel V, Cohen A, Dias A, Chowdhary N, Okereke OI, Dew MA, Anderson SJ, Mazumdar S, Lotrich F, Albert SM. Early intervention to reduce the global health and economic burden of major depression in older adults. Annu Rev Public Health. 2012; 33:123-135.

4. http://apps.who.int/gb/ebwha/pdf_files/EB130/B130_9-en.pdf

5. http://www.chinacdc.cn/

6. Yang G, Wang Y, Zeng Y, Gao GF, Liang X, Zhou M, Wan X, Yu S, Jiang Y, Naghavi M, Vos T, Wang H, Lopez AD, Murray CJ. Rapid health transition in China, 1990-2010: findings from the Global Burden of Disease Study 2010. 2013; 381 (9882) :1987-2015.

7. Rössler W, Salize HJ, van Os J, Riecher-Rössler A. Size of burden of schizophrenia and psychotic disorders. Eur Neuropsychopharmacol. 2005; 15 (4) : 399-409.

8. Lysaker PH, Vohs J, Hasson-Ohayon I, Kukla M, Wierwille J, Dimaggio G. Depression and insight in schizophrenia: comparisons of levels of deficits in social cognition and metacognition and internalized stigma across three profiles. Schizophr Res. 2013; 148(1-3):18-23. 
9. Owoeye O, Kingston T, Scully PJ, Baldwin P, Browne D, Kinsella A, Russell V, O'Callaghan E, Waddington JL. Epidemiological and clinical characterization following a first psychotic episode in major depressive disorder: comparisons with schizophrenia and bipolar I disorder in the Cavan-Monaghan First Episode Psychosis Study (CAMFEPS). Schizophr Bull. 2013; 39(4):756-765.

10. Häfner H, Maurer K, An der Heiden W. Schizophrenia - a disorder in its own right? : results from 25 years of the ABC study. 2013; 84(9):1093-4, 1096-1103.

11. Grady SE, Marsh TA, Tenhouse A, Klein K. Ketamine for the treatment of major depressive disorder and bipolar depression: A review of the literature. Ment Health Clin. 2018;7(1):16-23.

12. Kong J, Moorman SM. Caring for My Abuser: Childhood Maltreatment and Caregiver Depression. 2015;55(4):656-666.

13. de Monteynard LA, Younès N, Melchior M. Socio-demographic factors and use of health services for psychological reasons in young adults. Rev Epidemiol Sante Publique. 2013; 61(4):351-61.

14. Friedmann E, Son H, Thomas SA, Chapa DW, Lee HJ; Sudden Cardiac Death in Heart Failure Trial (SCDHeFT) Investigators. Poor social support is associated with increases in depression but not anxiety over 2 years in heart failure outpatients. J Cardiovasc Nurs. 2014; 29(1):20-8.

15. Kennedy JL, Altar CA, Taylor DL, Degtiar I, Hornberger JC. The social and economic burden of treatmentresistant schizophrenia: a systematic literature review. Int Clin Psychopharmacol. 2014;29(2):63-76..

16. McDonell MG, Short RA, Berry CM, Dyck DG. Burden in schizophrenia caregivers: impact of family psychoeducation and awareness of patient suicidality. Fam Process. 2003 ;42(1):91-103.

17. Feixas G, Bados A, García-Grau E, Montesano A, Dada G, Compañ V, Aguilera M, Salla M, Soldevilla JM, Trujillo A, Paz C, Botella L, Corbella S, Saúl-Gutiérrez LA, Cañete J, Gasol M, Ibarra M, Medeiros-Ferreira L, Soriano J, Ribeiro E, Caspar F, Winter D. Efficacy of a dilemma-focused intervention for unipolar depression: study protocol for a multicenter randomized controlled trial. $2013 ; 14: 144$.

18. Compton MT, McGlashan TH, McGorry PD. Toward Prevention Approaches for Schizophrenia: An Overview of Prodromal States, the Duration of Untreated Psychosis, and Early Intervention Paradigms. Psychiat Ann 2007;37:340-348.

19. Howes OD, Williams M, Ibrahim K, Leung G, Egerton A, McGuire PK, Turkheimer F. Midbrain dopamine function in schizophrenia and depression: a post-mortem and positron emission tomographic imaging study. 2013; 136 (Pt 11): 3242-51.

20. Ma XC, Chen C, Zhu F, Jia W, Gao CG. Association of the GDNF gene with depression and heroin dependence, but not schizophrenia, in a Chinese population. Psychiatry Res. 2013; 210(3):1296-8.

21. Wilson IB, Cleary PD. Linking clinical variables with health-related quality of life. A conceptual model of patient outcomes. JAMA. 1995;273(1):59-65.

22. Reine G, Simeoni MC, Auquier P, Loundou A, Aghababian V, Lancon C. Assessing health-related quality of life in patients suffering from schizophrenia: a comparison of instruments. Eur Psychiatry 2005;20(7):510-519.

23. Ferdiana A, Post MW, Finger M, Bültmann U, Escorpizo R. Assessment of health-related quality of life of clients in vocational rehabilitation: association with depressive symptoms and type of services. Eur $\mathrm{J}$ Phys Rehabil Med. 2014;50(3):343-353. 
24. Ware JE, Snow KK, Kosinski M, Gandek B: SF-36 Health Survey: Manual and Interpretation Guide Rhode Island: QualityMetric Incorporated: Lincoln 2000.

25. Sararaks S, Azman AB, Low LL, Rugayah B, Aziah AM, Hooi LN, Abdul Razak M, Norhaya MR, Lim KB, Azian AA, Geeta S. Validity and reliability of the SF-36: the Malaysian context. Med J Malaysia. 2005;60(2):163-179.

26. Adelufosi AO, Ogunwale A, Abayomi O, Mosanya JT. Socio-demographic and clinical correlates of subjective quality of life among Nigerian outpatients with schizophrenia. Psychiatry Res. 2013; 209(3):320-325.

27. Hamaideh S, Al-Magaireh D, Abu-Farsakh B, Al-Omari H. Quality of life, social support, and severity of psychiatric symptoms in Jordanian patients with schizophrenia. J Psychiatr Ment Health Nurs. 2014;21(5):455-465.

28. Pukrop R, Schlaak V, Möller-Leimkühler AM, Albus M, Czernik A, Klosterkötter J, Möller HJ. Reliability and validity of Quality of Life assessed by the Short-Form 36 and the Modular System for Quality of Life in patients with schizophrenia and patients with depression. Psychiatry Res. 2003;119(1-2):63-79.

29. Boyer L, Baumstarck K, Boucekine M, Blanc J, Lançon C, Auquier P. Measuring quality of life in patients with schizophrenia: an overview. Expert Rev Pharmacoecon Outcomes Res. 2013; 13(3):343-9.

30. BALHARA, Yatan Pal Singh. Prevention of Schizophrenia: A Review Turkish Journal of Psychiatry, 2013; $24(2): 1-9$.

31. Anita Patel1, Paul McCrone, Morven Leese, Francesco Amaddeo, Michele Tansella, Reinhold Kilian, Matthias Angermeyer, Martijn Kikkert, Aart Schene and Martin Knapp. Cost-effectiveness of adherence therapy versus health education for people with schizophrenia: randomised controlled trial in four European. Cost Effectiveness and Resource Allocation 2013, 11:12:1-13.

32. Kemp AH, Gordon E, Rush AJ, Williams LM. Improving the prediction of treatment response in depression: integration of clinical, cognitive, psychophysiological, neuroimaging, and genetic measures. CNS Spectr. 2008; 13(12):1066-86.

33. Winchester BR, Watkins SC, Brahm NC, Harrison DL, Miller MJ. Mental health treatment associated with community-based depression screening: considerations for planning multidisciplinary collaborative care. Ann Pharmacother. 2013; 47(6):797-804.

34. Drake RE, Frey W, Bond GR, Goldman HH, Salkever D, Miller A, Moore TA, Riley J, Karakus M, Milfort R. Assisting Social Security Disability Insurance Beneficiaries With Schizophrenia, Bipolar Disorder, or Major Depression in Returning to Work. Am J Psychiatry. 2013;170(12):1433-1441.

35. Wu G, Ouyang X, Yang B, Li L, Wang Z, Yi W, Liu C, Wang P, Chiu HF, Lee E, Xue Z, Rosenheck R, Liu Z. Long- and short-term inpatients with schizophrenia in China: implications for community-based service development. Asia Pac Psychiatry. 2013 ;5(1):E39-46.

\section{Tables}


Table 1

The socio-demographic characteristics of participants

\begin{tabular}{|c|c|c|c|c|}
\hline \multirow[t]{2}{*}{ Characteristics } & \multicolumn{2}{|c|}{$\begin{array}{l}\text { Depression } \\
(\mathrm{N}=135)\end{array}$} & \multicolumn{2}{|c|}{$\begin{array}{l}\text { Schizophrenia } \\
(N=69)\end{array}$} \\
\hline & $\mathrm{n}$ & $\%$ & $\mathbf{n}$ & $\%$ \\
\hline \multicolumn{5}{|l|}{ Gender } \\
\hline Male & 60 & 44.4 & 31 & 44.9 \\
\hline Female & 75 & 55.6 & 38 & 55.1 \\
\hline \multicolumn{5}{|l|}{ Marital status } \\
\hline Unmarried & 47 & 34.8 & 32 & 46.4 \\
\hline Married & 83 & 61.5 & 32 & 46.4 \\
\hline Devoice/Widowed & 5 & 3.7 & 5 & 7.2 \\
\hline \multicolumn{5}{|l|}{ Age } \\
\hline$<30$ & 37 & 27.4 & 33 & 47.8 \\
\hline $30-39$ & 41 & 30.4 & 25 & 36.2 \\
\hline $40-49$ & 25 & 18.5 & 2 & 2.9 \\
\hline $50-59$ & 20 & 14.9 & 4 & 5.9 \\
\hline$\geq 60$ & 12 & 8.8 & 5 & 7.2 \\
\hline$x \pm s$ & \multicolumn{2}{|c|}{$39.17 \pm 13.80$} & \multicolumn{2}{|c|}{$33.00 \pm 14.09$} \\
\hline \multicolumn{5}{|l|}{ Ethnicity } \\
\hline Han & 115 & 85.2 & 62 & 89.9 \\
\hline Minority & 20 & 14.8 & 7 & 10.1 \\
\hline \multicolumn{5}{|l|}{ Education } \\
\hline Primary school/illiterate & 13 & 9.6 & 6 & 8.7 \\
\hline High school & 60 & 44.4 & 42 & 60.9 \\
\hline University/higher & 62 & 45.9 & 21 & 30.4 \\
\hline \multicolumn{5}{|l|}{ Inhabited area } \\
\hline Large and medium-sized city & 112 & 83.0 & 43 & 62.3 \\
\hline Small-sized city & 17 & 12.6 & 11 & 15.9 \\
\hline Rural area & 6 & 4.4 & 15 & 21.7 \\
\hline
\end{tabular}


Table 2

The main disease characteristics of participated patients

\begin{tabular}{|c|c|c|c|c|}
\hline \multirow[t]{2}{*}{ Characteristics } & \multicolumn{2}{|c|}{ Depression $(\mathrm{N}=135)$} & \multicolumn{2}{|c|}{ Schizophrenia $(N=69)$} \\
\hline & $\mathbf{n}$ & $\%$ & $\mathbf{n}$ & $\%$ \\
\hline \multicolumn{5}{|l|}{ Onset form } \\
\hline Acute & 24 & 17.8 & 22 & 31.9 \\
\hline Sub-acute & 55 & 40.7 & 24 & 34.8 \\
\hline Chronic & 56 & 42.5 & 23 & 33.3 \\
\hline \multicolumn{5}{|l|}{ Severity degree } \\
\hline Mild & 46 & 34.1 & 19 & 27.5 \\
\hline Moderate & 80 & 59.3 & 46 & 66.7 \\
\hline Severe & 9 & 6.7 & 4 & 5.8 \\
\hline \multicolumn{5}{|l|}{ Duration of disease } \\
\hline$x \pm s$ & \multicolumn{2}{|c|}{$4.44 \pm 4.12$} & \multicolumn{2}{|c|}{$5.58 \pm 7.31$} \\
\hline \multicolumn{5}{|l|}{ Treatment duration } \\
\hline$\leq$ Six months & 25 & 18.5 & 16 & 23.2 \\
\hline Six months-one year & 10 & 7.4 & 3 & 4.3 \\
\hline Thirteen months-two years & 14 & 10.4 & 11 & 15.9 \\
\hline Twenty-five months-three years & 10 & 7.4 & 1 & 1.4 \\
\hline Thirty-seven months-five years & 30 & 22.2 & 11 & 15.9 \\
\hline Sixty-one months-ten years & 31 & 23.0 & 17 & 24.6 \\
\hline$>$ ten years & 15 & 11.1 & 10 & 14.5 \\
\hline$M \pm Q$ & \multicolumn{2}{|c|}{$3.30 \pm 5.40$} & \multicolumn{2}{|c|}{$4.20 \pm 6.05$} \\
\hline
\end{tabular}


Table 3

Univariate statistical comparison of socio-demographic of participated patients

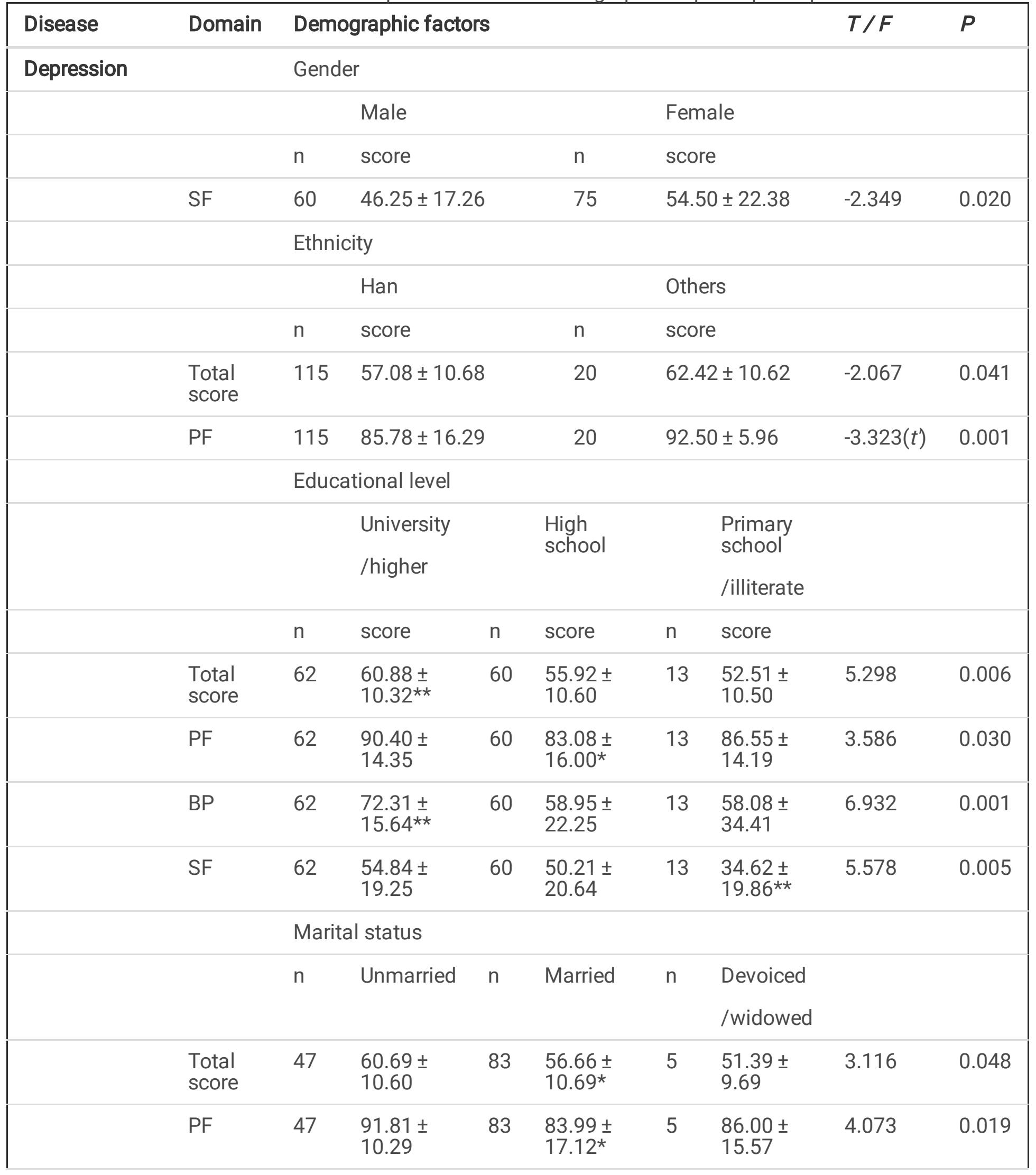

(1) * indicate that there are statistical differences compared with the first groups. (2) ** indicate that there are statistical differences through multiple comparisons. 


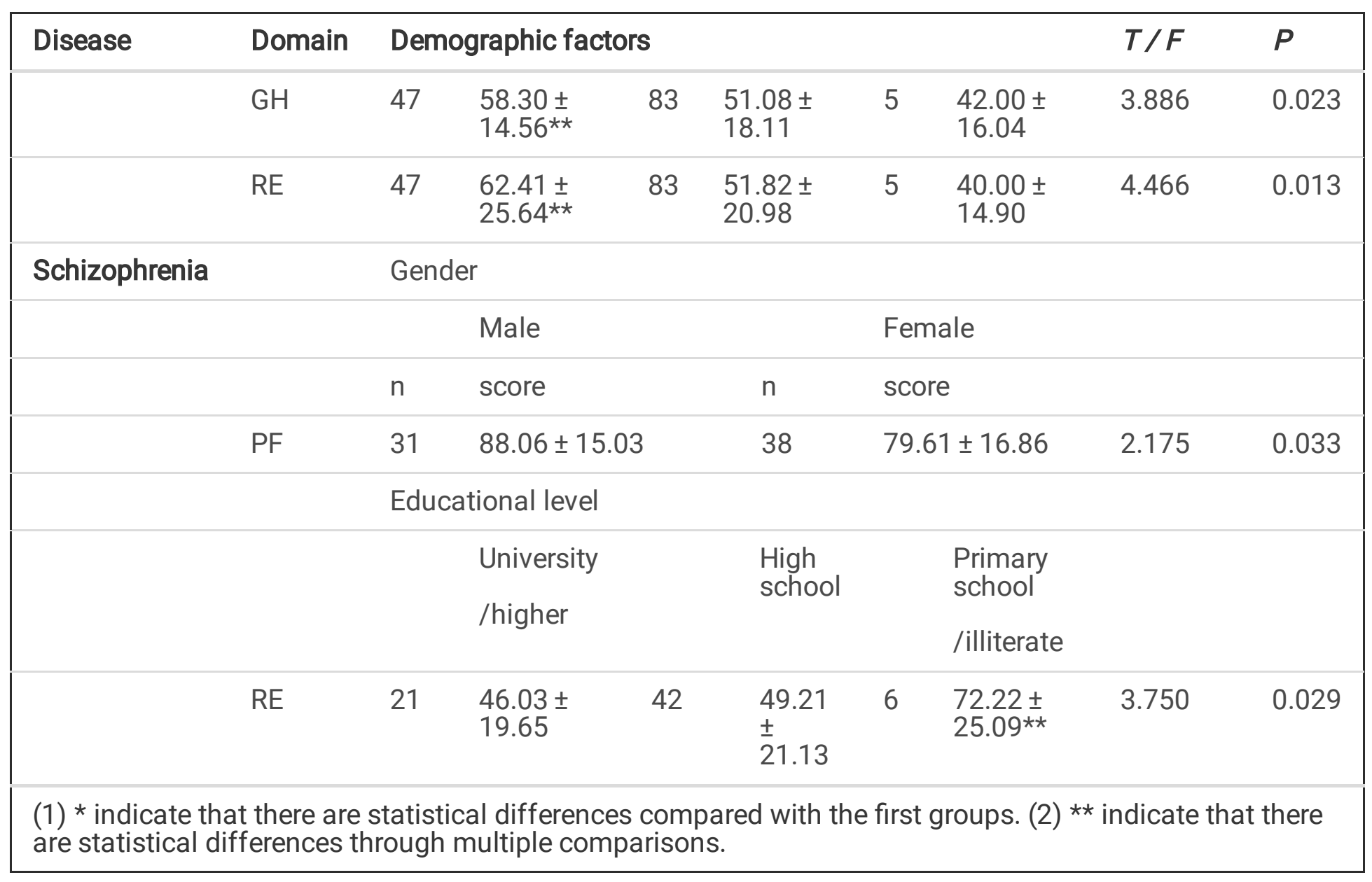


Table 4

Comparison of the SF-36 scores of patients with depression, schizophrenia and healthy people $(x \pm s)$

\begin{tabular}{|c|c|c|c|c|c|}
\hline Domain & $\begin{array}{l}\text { Depression } \\
(n=135)\end{array}$ & $\begin{array}{l}\text { Schizophrenia } \\
(n=69)\end{array}$ & $\begin{array}{l}\text { Healthy } \\
\text { people } \\
(n=136)\end{array}$ & $F$ & $P$ \\
\hline Total score of SF-36 & $\begin{array}{l}57.87 \pm \\
10.80\end{array}$ & $55.32 \pm 8.56$ & $\begin{array}{l}80.29 \pm \\
10.36^{\star}\end{array}$ & 213.759 & $\stackrel{<}{0.001}$ \\
\hline Physical functioning (PF) & $\begin{array}{l}86.78 \pm \\
15.38\end{array}$ & $83.41 \pm 16.50$ & $\begin{array}{l}91.86 \pm \\
16.19^{*}\end{array}$ & 7.235 & $<.001$ \\
\hline Role physical (RP) & $\begin{array}{l}53.52 \pm \\
20.19\end{array}$ & $46.38 \pm 18.82$ & $\begin{array}{l}90.24 \pm \\
17.09 \star \star\end{array}$ & 181.572 & $\begin{array}{l}< \\
0.001\end{array}$ \\
\hline Bodily pain (BP) & $\begin{array}{l}65.00 \pm \\
21.93\end{array}$ & $67.58 \pm 20.46$ & $\begin{array}{l}82.00 \pm \\
28.62^{\star}\end{array}$ & 21.562 & $\dot{0}_{0.001}$ \\
\hline General health (GH) & $\begin{array}{l}53.26 \pm \\
17.25\end{array}$ & $50.58 \pm 15.93$ & $\begin{array}{l}67.86 \pm \\
19.31^{\star}\end{array}$ & 31.278 & $\stackrel{<}{0.001}$ \\
\hline Vitality (VT) & $\begin{array}{l}50.67 \pm \\
15.49\end{array}$ & $48.69 \pm 16.70$ & $\begin{array}{l}69.78 \pm \\
16.50 *\end{array}$ & 61.563 & $<.001$ \\
\hline Social functioning (SF) & $\begin{array}{l}50.83 \pm \\
20.61\end{array}$ & $53.26 \pm 22.75$ & $\begin{array}{l}87.32 \pm \\
18.23^{*}\end{array}$ & 128.033 & $\begin{array}{l}< \\
0.001\end{array}$ \\
\hline Role emotional (RE) & $\begin{array}{l}55.06 \pm \\
23.15\end{array}$ & $50.24 \pm 21.86$ & $\begin{array}{l}78.20 \pm \\
18.84^{\star}\end{array}$ & 56.594 & $\dot{0}_{0.001}$ \\
\hline Mental health $(\mathrm{MH})$ & $\begin{array}{l}47.82 \pm \\
16.90\end{array}$ & $42.38 \pm 17.72$ & $\begin{array}{l}75.10 \pm \\
14.29 \star \star\end{array}$ & 136.333 & $\stackrel{<}{0.001}$ \\
\hline $\begin{array}{l}\text { Physical Component Summary } \\
\text { (PCS) }\end{array}$ & $58.62 \pm 8.24$ & $57.31 \pm 10.91$ & $\begin{array}{l}77.46 \pm \\
15.91^{\star}\end{array}$ & 51.392 & $\dot{0}_{0.001}$ \\
\hline $\begin{array}{l}\text { Mental Component Summary } \\
\text { (MCS) }\end{array}$ & $50.68 \pm 7.55$ & $50.42 \pm 7.53$ & $\begin{array}{l}71.68 \pm \\
17.73^{\star}\end{array}$ & 53.286 & $<.001$ \\
\hline
\end{tabular}


Table 5

Quantization of Independence variables

\begin{tabular}{|c|c|c|c|c|c|}
\hline Factor & $\begin{array}{l}\text { Variable } \\
\text { name }\end{array}$ & quantization & Factor & $\begin{array}{l}\text { Variable } \\
\text { name }\end{array}$ & quantization \\
\hline Gender & $x_{1}$ & Male $=1$,Female $=2$ & $\begin{array}{l}\text { Living in Large and } \\
\text { medium-sized city }\end{array}$ & $x_{10}$ & $\begin{array}{l}\text { No }=0, \text { Yes }= \\
1\end{array}$ \\
\hline Age & $x_{2}$ & Years old & $\begin{array}{l}\text { Living in small- } \\
\text { sized city }\end{array}$ & $x_{11}$ & $\begin{array}{l}\text { No }=0, \text { Yes }= \\
1\end{array}$ \\
\hline Ethnicity & $x_{3}$ & Han $=1$, Minority $=2$ & Living in rural area & $x_{12}$ & $\begin{array}{l}\text { No }=0, \text { Yes }= \\
1\end{array}$ \\
\hline Unmarried & $x_{4}$ & $\mathrm{No}=0, \mathrm{Yes}=1$ & Duration of disease & $x_{13}$ & Year \\
\hline $\begin{array}{l}\text { Married/ } \\
\text { Premarital } \\
\text { Cohabitation }\end{array}$ & $x_{5}$ & No $=0, Y e s=1$ & Severity degree & $x_{14}$ & $\begin{array}{l}\text { Light }=1, \\
\text { Medium = 2, } \\
\text { Severe = } 3\end{array}$ \\
\hline $\begin{array}{l}\text { Devoice/ } \\
\text { Widowed }\end{array}$ & $x_{6}$ & $\mathrm{No}=0, \mathrm{Yes}=1$ & Onset form & $x_{15}$ & $\begin{array}{l}\text { Acute }=1, \\
\text { Sub-acute = } \\
2, \\
\text { Chronic = } 3\end{array}$ \\
\hline $\begin{array}{l}\text { Educational } \\
\text { level }\end{array}$ & $x_{7}$ & $\begin{array}{l}\text { Primary school/ } \\
\text { illiterate }=1, \text { High } \\
\text { school }=2 \square \\
\text { University } / \text { higher = } 3\end{array}$ & $\begin{array}{l}\text { Changing of health } \\
\text { status }\end{array}$ & $x_{16}$ & $\begin{array}{l}\text { Changing } \\
\text { worse } \\
\text { extremely = } \\
1 \text {, } \\
\text { Changing } \\
\text { worse } \\
\text { slightly = 2, } \\
\text { No } \\
\text { changing = } \\
3 \text {, } \\
\text { Changing } \\
\text { better = 4, } \\
\text { Changing } \\
\text { better } \\
\text { extremely = } \\
5\end{array}$ \\
\hline $\begin{array}{l}\text { Annual family } \\
\text { income }\end{array}$ & $x_{8}$ & Ten thousand yuan & Direct cost & $x_{17}$ & $\begin{array}{l}\text { Ten } \\
\text { thousand } \\
\text { yuan }\end{array}$ \\
\hline $\begin{array}{l}\text { experiencing } \\
\text { critical life } \\
\text { events }\end{array}$ & $x_{9}$ & No $=0, Y e s=1$ & Indirect cost & $x_{18}$ & $\begin{array}{l}\text { Ten } \\
\text { thousand } \\
\text { yuan }\end{array}$ \\
\hline
\end{tabular}


Table 6

Predictors impacting on HRQOL of patients with Depression/Schizophrenia selected by stepwise multiple linear regressions

\begin{tabular}{|c|c|c|c|c|c|}
\hline \multirow[t]{2}{*}{$\begin{array}{l}\text { Disease } \\
\text { /Domain }\end{array}$} & \multirow[t]{2}{*}{ Factors } & $\begin{array}{l}\text { Un- } \\
\text { standardized } \\
\text { coefficients }\end{array}$ & $\begin{array}{l}\text { Standardized } \\
\text { coefficients }\end{array}$ & $P$ & $\begin{array}{l}\text { Co-linearity } \\
\text { statistics }\end{array}$ \\
\hline & & $\begin{array}{l}\text { Std. } \\
\text { Error }\end{array}$ & Beta & & Tolerance \\
\hline
\end{tabular}

Depression

\begin{tabular}{lllllllll}
$\begin{array}{l}\text { Physical } \\
\text { Component } \\
\text { Summary (PCS) }\end{array}$ & Constant & 73.14 & 3.07 & & 23.83 & 0.00 & & \\
\cline { 2 - 4 } & -2.89 & 0.67 & -0.33 & -4.30 & 0.00 & 0.99 & 1.01 \\
& $\begin{array}{l}\text { Subject } \\
\text { change of } \\
\text { health status }\end{array}$ & & & & & & & \\
& $\begin{array}{l}\text { Severity } \\
\text { degree }\end{array}$ & -3.21 & 1.10 & -0.23 & -2.90 & 0.00 & 1.00 & 1.00 \\
& $\begin{array}{l}\text { Unmarried } \\
\text { status }\end{array}$ & 3.02 & 1.34 & 0.18 & 2.26 & 0.03 & 0.99 & 1.01
\end{tabular}

Adjusted R Square $=0.20, F=7.38, P=0.00$

\begin{tabular}{lllllllll}
$\begin{array}{l}\text { Mental } \\
\text { Component }\end{array}$ & Constant & 42.55 & 2.34 & & 19.01 & 0.00 & \\
$\begin{array}{l}\text { Summary } \\
(\text { MCS) }\end{array}$ & $\begin{array}{l}\text { Unmarried } \\
\text { status }\end{array}$ & 4.04 & 1.30 & 0.26 & 3.10 & 0.00 & 1.00 & 1.03 \\
\cline { 2 - 9 } & Ethnicity & 4.50 & 1.72 & 0.21 & 2.61 & 0.01 & 1.00 & 1.00 \\
& $\begin{array}{l}\text { Duration of } \\
\text { disease }\end{array}$ & 0.35 & 0.15 & 0.19 & 2.32 & 0.02 & 0.97 & 1.03 \\
& & & & & & &
\end{tabular}

Adjusted $\mathrm{R}$ Square $=0.11, \mathrm{~F}=7.11, \mathrm{P}=0.00$

Schizophrenia

\begin{tabular}{|c|c|c|c|c|c|c|c|c|}
\hline \multirow{6}{*}{$\begin{array}{l}\text { Physical } \\
\text { Component } \\
\text { Summary (PCS) }\end{array}$} & Constant & 72.70 & \multicolumn{2}{|l|}{6.30} & 11.54 & \multicolumn{3}{|l|}{0.00} \\
\hline & $\begin{array}{l}\text { Subjective } \\
\text { change of } \\
\text { health status }\end{array}$ & -2.11 & 0.93 & -0.24 & -2.26 & 0.03 & 0.87 & 1.15 \\
\hline & $\begin{array}{l}\text { Annual } \\
\text { family } \\
\text { income }\end{array}$ & 1.97 & 0.48 & 0.43 & 4.14 & 0.00 & 0.87 & 1.15 \\
\hline & $\begin{array}{l}\text { Education } \\
\text { level }\end{array}$ & -5.51 & 1.90 & -0.30 & -2.91 & 0.01 & 0.90 & 1.11 \\
\hline & $\begin{array}{l}\text { Severity } \\
\text { degree }\end{array}$ & 6.28 & 2.10 & 0.31 & 3.00 & 0.00 & 0.89 & 1.13 \\
\hline & Ethnicity & -10.19 & 3.72 & -0.28 & -2.74 & 0.01 & 0.88 & 1.13 \\
\hline
\end{tabular}

B: Regression coefficient, Beta: Standardized Coefficients of B 


\begin{tabular}{|c|c|c|c|c|c|c|c|c|}
\hline \multirow[t]{2}{*}{$\begin{array}{l}\text { Disease } \\
\text { /Domain }\end{array}$} & \multirow[t]{2}{*}{ Factors } & \multicolumn{2}{|c|}{$\begin{array}{l}\text { Un- } \\
\text { standardized } \\
\text { coefficients }\end{array}$} & \multirow{2}{*}{$\begin{array}{l}\text { Standardized } \\
\text { coefficients } \\
\text { Beta }\end{array}$} & \multirow[t]{2}{*}{$t$} & \multirow[t]{2}{*}{$P$} & \multicolumn{2}{|l|}{$\begin{array}{l}\text { Co-linearity } \\
\text { statistics }\end{array}$} \\
\hline & & B & $\begin{array}{l}\text { Std. } \\
\text { Error }\end{array}$ & & & & Tolerance & VIF \\
\hline & & \multicolumn{7}{|c|}{ Adjusted R Square $=0.36, F=8.76, P=0.00$} \\
\hline \multirow{3}{*}{$\begin{array}{l}\text { Mental } \\
\text { Component } \\
\text { Summary } \\
\text { (MCS) }\end{array}$} & Constant & 57.97 & 3.35 & & 17.31 & 0.00 & & \\
\hline & Ethnicity & -6.80 & 2.93 & -0.28 & -2.32 & 0.02 & 1.00 & 1.00 \\
\hline & & \multicolumn{7}{|c|}{ Adjusted R Square $=0.06, F=7.34, P=0.02$} \\
\hline
\end{tabular}

